\title{
Renal Pelvis and Ureter Cancer by AJCC v7 Stage
}

National Cancer Institute

\section{Source}

National Cancer Institute. Renal Pelvis and Ureter Cancer by AJCC v7 Stage. NCI

Thesaurus. Code C140376.

A term that refers to the staging of renal pelvis and ureter cancer according to the American Joint Committee on Cancer, 7th edition. 